\title{
Don't Miss the Boat, Mini-Conference Presenters Urge
}

\author{
Sophia D. Merow
}

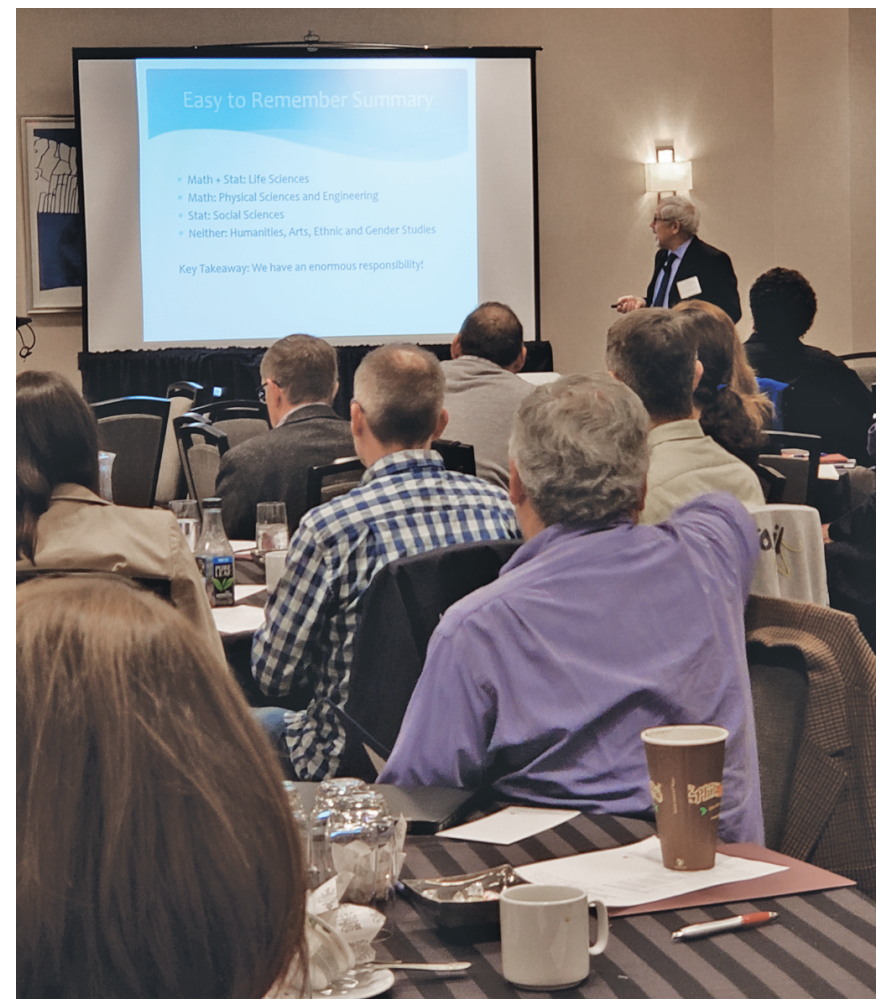

Figure 1. Mark Green addresses attendees at October 2019's Mini-conference on Education.

Sophia D. Merow is a freelance writer and editor. Her email address is sdmerow@gmai 1 . com.

For permission to reprint this article, please contact: reprint-permission aams.org.

DOI: https://dx.doi.org/10.1090/noti2092
In preparation for his presentation at the AMS Committee on Education's second annual Mini-conference on Education in October 2019, Mark Green (UCLA) completed an exercise one meeting attendee admiringly called "kind of pedantic": He examined all of UCLA's 135 majors and 94 minors to determine the state of quantitative play on campus. Which majors require math? Stat? Math and stat? Which majors have computational components? Which departments teach quantitative courses, and what is the nature of these offerings?

The conclusion of Green's deep dive into the UCLA course catalog? "The role of math has changed," Green told the 100 thronging the DC Marriott meeting room. More disciplines use math in more ways today than they did in decades past, Green said, and to provide students with an education optimized for this new reality, the math community will need to adapt to the changed-and rapidly changing_landscape. "The more gray hair you have," the emeritus professor quipped, "the more adaptation is probably necessary."

Titled "Mathematics Departments and the Explosive Growth of Computational and Quantitative Offerings in Higher Education," the daylong conference Green headlined portrayed a proliferation of computational and quantitative majors, minors, specializations, and certificates as a challenge for mathematics faculty, yes, but also an opportunity.

Being a math professor can be a relatively cushy gig. Clear the tenure hurdle and one can complacently communicate the same uncontroversial (if demanding) material semester after semester. Both Green and fellow presenter Michael Dorff (BYU), however, emphasized the imperative of mathematicians venturing into an instructional space where 


\section{EDUCATION}

\section{What You Should Do}

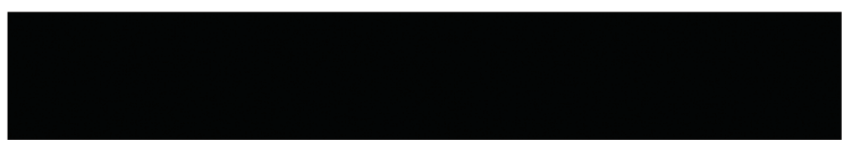

\section{Thank you!}

$*$ Be curious

$*$ Be proactive

$*$ Be willing to go outside your comfort zone

$*$ Get plugged into existing efforts

\author{
Michael Dorff \\ mdorff@math.byu.edu \\ Twitter (@mdorff44)
}

Get out of your comfort zone!

Figure 2. Both Green (left) and Dorff (right) urged attendees to leave their comfort zones.

answers are less definitive than they're used to, professorial authority less absolute. "When you teach calculus, a student is not going to say, 'Wait a minute, I don't believe the fundamental theorem of calculus,', explained Green. "You feel like we've got it nailed down." But start talking about, say, how an Ohio town should be divided into police beats to equitably reflect population distribution, and suddenly differences of opinion can legitimately arise.

The police beats example comes from Dorff's overview of the Mathematical Association of America's NSF-funded Preparation for Industrial Careers in Mathematical Sciences (PIC Math) program, which trains professors to teach an undergraduate course based on real-world problems sourced from partners in business, industry, or government (see https://bit. 1y/351z34H). Dorff knows how daunting such a prospect can be for mathematicians accustomed to assigning familiar, precisely formulated exercises from within a circumscribed subfield. "You're going to actually have to work on a problem that you don't know how to solve and that your students don't know how to solve, and you have to be okay with that," he said. In industry, Dorff stressed, problems don't fall neatly into one classification or another. When today's math major lands a job in industry after graduation, no supervisor is "going to say, 'Here's a problem that we want you to solve for our company and we want you to use linear programming to do it,'" Dorff said. "They're just going to say, 'Here's the problem. Good luck.'"

Dorff spoke in the afternoon, when conference-goers had already heard presenters detail impressive data science initiatives underway at Smith, Johns Hopkins, and Macalester, and he explicitly addressed listeners' likely doubts about successfully implementing comparably ambitious programs at their own institutions, their probable feelings of relative ignorance. "I was at the same stage lots of you are at twenty years ago," he confessed. "I didn't know anything about careers in math except for that you could be an actuary." But with the goal in mind- "We want to help students, and that's why we do this" —and an adventurous spirit, preparing undergrads for careers outside academia is possible. "You can't do this if you want to just feel safe doing what you've always done," Dorff said. "But if you're willing to get out of your comfort zone and think outside the box, then you can do this."

As mathematicians either do as Dorff urges-get up to speed with twenty-first-century uses of mathematics and reassert the math department's centrality to quantitative education-or fail to, much is at stake, Dorff and Green intimated. And time is of the essence.

Mathematicians risk, for one thing, forgoing a once-ina-lifetime opportunity to get in early on something big. "If you ever feel like 'gee, I wish I'd been around when elliptic curves were getting started' or put your favorite field there," Green said, "well here's something that is getting started and you are around."

And then there's the interdisciplinary tussle for primary custody of data science. Is data science statistics? Computer science? What about at universities where the most robust data science offerings are in the business school? Having heard someone at an AAAS meeting claim that data science falls under biology, Dorff exhorted mini-conference attendees not to "miss the boat." "If we keep hiding our heads in the math department," he said, "data science will go to other groups."

Green, for his part, believes that mathematicians are uniquely positioned to rise to today's Big Data occasion, and suspects that slow-to-respond colleagues will rue their inertia eventually. "You're going to regret this," he warned, channeling Bogart in Casablanca, "not now but soon and for the rest of your life." 
Green was, of course, preaching to the choir. Those who came to DC for the mini-conference did so because they recognize the change afoot and appreciate that the math community must evolve accordingly. "You know it needs to happen," Green told them. "But those who are not here don't always know that."

Conference-goers left encouraged to be curious about what people do with math nowadays and proactive about goading their home departments into reevaluating course content, sequencing, and requirements in light of these realities. If a colleague of yours attended the meeting, perhaps she returned keen to start a speaker series to expose students to professionals using mathematics beyond the ivory tower or adamant about reconsidering whether Calc II should really be a prerequisite for Linear Algebra. Maybe he came back raving about opencasestudi es . gi thub. io or vowing to undertake a Green-style analysis of the course catalog. Or urging you to attend the third annual Miniconference on Education to be held virtually on October 23, 2020. The theme is "Current issues: What can we do to support math majors and graduate students in the time of pandemic," and registration opens in July 2020. See https://www . ams . org/coemini conference for details.

In the meantime, slides from the 2019 mini-conference are available at https://bit.7y/2Mwtjsy

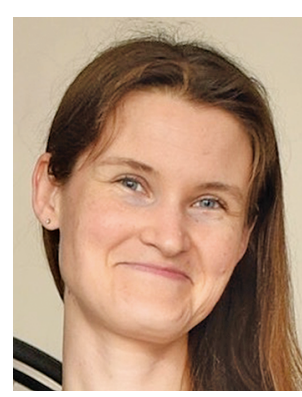

Sophia D. Merow

Credits

Figure 1 photo is by Anita Benjamin.

Figure 2 slides reproduced with permission from Mark Green and Michael Dorff.

Author photo is by Igor Tolkov.

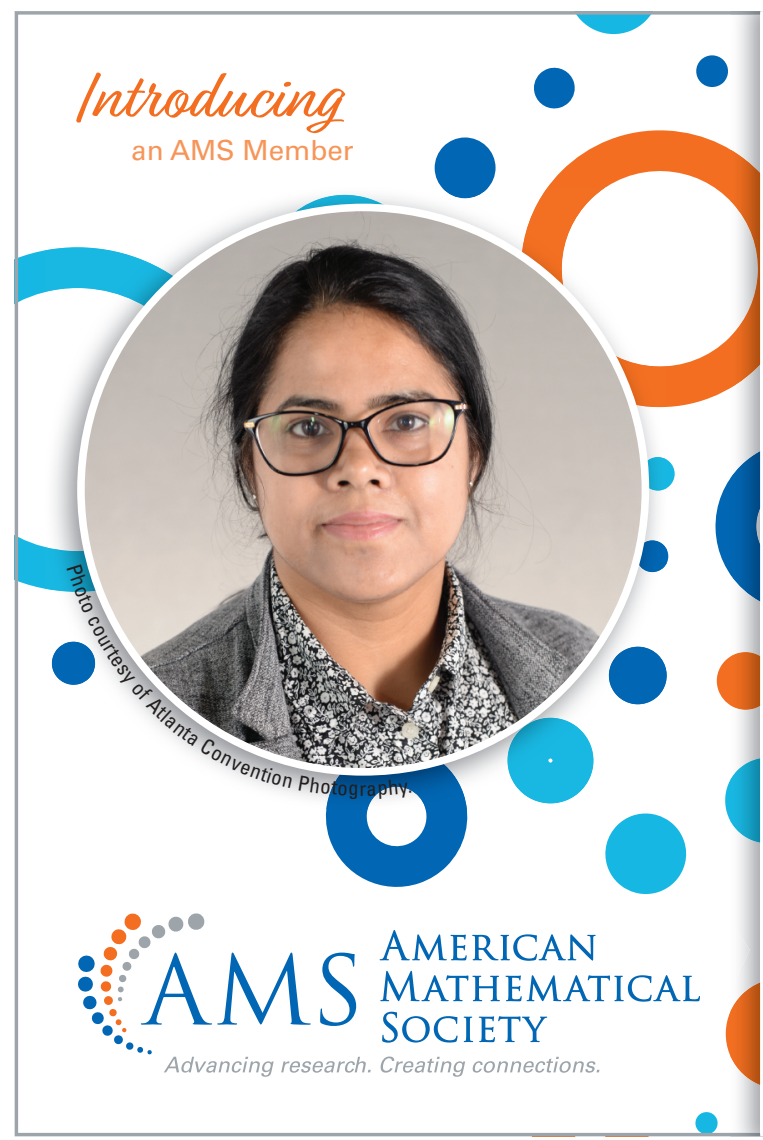

\section{PreetiDubey}

Post-Doc Research Associate, Loyola University-Chicago
AMS Member since: 2018

Primary Field Mathematical of Research: Modeling of Infectious Diseases

Dissertations Advisor: Prof. Balram Dubey Undergrad Institution:

PhD Institution: CSJM University Kampur
Favorite Number: 5

Favorite Color: Pink

Favorite Food: Indian Food

Erdős Number:

Favorite Hobby: Musical Composition

Describe the situation when you first fell for math

From childhood. I was very much interested in mathematics and after my scores in math during my 8th grade (which was average), my father was against my further education in math. So, I did a hunger strike for two days and then my father granted me half-hearted permission to do math for further education. Here I am now doing post-doc studies in mathematical modeling!

Were you inspired by a mathematician?

My father is my role model. He can do any calculation without using a calculator!

How would you describe math to a non-math person?

I think everybody has to do basic math in daily life, so without math there is nothing. Regarding higher education in math, by learning mathematics it makes us feel more confident, independent, more thoughtful. For me, math is beautiful as I can make predictions about the development of drugs for viral infections which can save money and lives. 